\title{
ESCOLA E ORGANIZAÇÃO NÃO GOVERNAMENTAL: educação formal e não-formal de jovens da periferia de Fortaleza
}

\author{
Isaurora Cláudia Martins de Freitas ${ }^{*}$
}

\section{INTRODUÇÃO}

O presente artigo $^{1}$ analisa, a partir das trajetórias de sete jovens egressos da Escola de Dança e Integração Social para Crianças e Adolescentes (EDISCA), as repercussões dessa experiência educativa na vida escolar dos ex-alunos, buscando perceber como as relações de complementaridade e "concorrência", verificadas entre a Organização Não Governamental (ONG) e a escola formal, repercutiram na formação desses jovens, sobretudo no que se refere à construção de novas perspectivas de inserção social e profissional.

O interesse pelo estudo dessa escola, reflexo do interesse pelas instituições que realizam trabalho de arte-educação com crianças e adolescentes das camadas desfavorecidas da população, resulta da constatação de que, no Brasil, desde meados dos anos

* Professor-Doutor da Universidade Estadual Vale do Acaraú . Av. da Universidade, 850 - Campus da Betânia, Sobral - Ceará. Cep: 62.040 - 370. Fone: (088) 3677-4243. isaurora@terra.com.br

${ }^{1} \mathrm{~A}$ pesquisa que sustenta este artigo foi apresentada como dissertação no mestrado em Sociologia da Universidade Federal do Ceará, intitulada "Da periferia ao palco: a ressocialização de crianças e adolescentes da periferia de Fortaleza através da arte".
90, havia crescente tendência de se tomar a arte como instrumento pedagógico mais apropriado para a "transformação da vida" de crianças e adolescentes ditas "em situação de risco", ${ }^{2}$ ou seja, as que, por causa da origem social, são consideradas como potencialmente aptas a assumir comportamentos considerados "desviantes", como criminalidade e prostituição. Tal tendência tem, nas iniciativas de educação não-formal implementadas pelas ONGs, após a promulgação do Estatuto da Criança e do Adolescente (ECA), seus principais ícones.

Interessada em discutir os resultados dos processos de educação pela arte, implementados por ONGs brasileiras, tomei a EDISCA como campo empírico de estudo por ser ela apontada pelas financiadoras, UNESCO e Instituto Ayrton Senna, como exemplo ou modelo de experiência bem sucedida de arte-educação no trato com o referido público.

A EDISCA atende a um público formado por crianças e adolescentes oriundos de famílias de baixa-renda. São filhos de pescadores, domés-

${ }^{2}$ Essa expressão era comumente utilizada pelos projetos sociais na década de 90 para designar o público-alvo de suas ações. Atualmente, a expressão foi substituída por outra, considerada menos estigmatizante: crianças "em situação de vulnerabilidade social”. 
ticas, vendedores ambulantes, desempregados, o que os coloca em condições socioeconômicas desfavoráveis para usufruto dos bens e serviços que a sociedade produz. Carências nutricionais, ausência do que, em sociedade, é classificado como "bons modos", "boa higiene", cuidados com a saúde, dentre outros, formam o leque de necessidades que, no entender da ONG, precisam ser trabalhadas para livrar essas pessoas do "risco" que a periferia oferece, oportunizando a construção de novas possibilidades de inserção social.

Assim, aulas de dança, palestras educativas, aquisição de novos hábitos alimentares, bem como de cuidados com a higiene e a saúde do corpo, dentre outras atividades, compõem a educação que esta escola propicia. Tal educação é apresentada pela ONG como complementar à proporcionada pela escola formal e pela família.

Considerando a educação como um fenômeno amplo, que engloba processos de natureza diversa, para além das escolas convencionais, é que tomo a EDISCA como instituição educacional. Assim, adoto o termo educação não-formal para classificar a natureza da educação processada na ONG, diferenciando-a da educação formal e da informal, tal como o faz Afonso (1989). A primeira é aquela organizada com uma determinada seqüência e proporcionada pelas escolas convencionais. A segunda abrange todas as possibilidades educativas no decurso da vida do indivíduo, constituindo um processo permanente e não organizado. A educação não-formal, portanto, embora obedeça também a uma estrutura e a uma organização (distintas, porém, das escolas) e possa levar a uma certificação, diverge da educação formal no que respeita à não fixação de tempos e locais e à flexibilidade na adaptação dos conteúdos de aprendizagem a cada grupo concreto.

É importante ressaltar também que a educação, em suas diversas modalidades, é tomada, neste trabalho, como processo de socialização em que são geradas as disposições do habitus, ou seja, os esquemas de percepção, pensamento e ação dos indivíduos (Bourdieu, 1989). Dessa forma, a perspectiva da socialização como incorporação do habitus, adotada neste estudo, é a mesma proposta por Dubar:

um processo biográfico de incorporação das disposições sociais vindas não somente da família e da classe de origem, mas também do conjunto dos sistemas de ação com os quais o indivíduo se cruzou no decorrer da sua existência (Dubar, 1997, p. 77).

A noção de trajetória, metodologicamente central na minha pesquisa, é entendida como uma série de colocações e deslocamentos do indivíduo no espaço social, submetido a constantes transformações (Bourdieu, 2005; Pais, 2003; Mauger, 1989). As trajetórias revelam as disposições constituídas em diferentes processos de socialização pelos quais o indivíduo passou. Assim, a reconstituição das trajetórias dos ex-alunos da EDISCA, efetivada a partir das entrevistas em profundidade, permitiu a percepção dos reflexos das várias pertenças e deslocamentos na constituição do sistema de crenças, anseios e práticas que orientam o encaminhamento de suas vidas no presente, bem como a percepção das relações de complementaridade e "concorrência” entre diferentes espaços de socialização. Para fins deste artigo, destaquei a relação entre ONG e escola formal, buscando perceber como as relações de complementaridade e "concorrência" verificadas entre essas instituições repercutiram na formação dos jovens em questão.

O texto está dividido em três partes. Na primeira, apresento a escoal de dança, seus objetivos e as atividades e serviços oferecidos aos alunos, para dar ao leitor uma idéia da socialização proporcionada pela ONG. Em seguida, apresento meus entrevistados, reconstituindo as trajetórias de três deles e, por último, analiso, a partir da fala desses jovens, como esta organização não governamental e escola formal se complementaram e (ou) concorreram na tessitura das trajetórias de vida.

\section{A "EDISCA" E A EDUCAÇÃO PELA DANÇA}

A Escola de Dança e Integração Social para Crianças e Adolescentes (EDISCA) é um exemplo 
paradigmático dos novos discursos e práticas, implementados em relação às crianças e adolescentes no período pós Estatuto da Criança e do Adolescente (ECA). Sua atuação está inscrita, principalmente, nos parâmetros de atendimento que visam a um trabalho socioeducativo com pretensões emancipadoras, baseado nas noções de cidadania e desenvolvimento humano. A ONG, utiliza a arte como aporte pedagógico, perseguindo a seguinte missão: Promover o desenvolvimento humano de crianças e adolescentes visando formar cidadãos sensíveis, criativos e éticos através de uma pedagogia transformadora com centralidade na arte.

Esta escola surgiu em 1991, quando uma bailarina e coreógrafa de Fortaleza conseguiu um patrocínio da Secretaria de Cultura do Estado para sua companhia de dança. Em contrapartida, os bailarinos da Companhia ministrariam aulas de dança para crianças da periferia de Fortaleza. A equipe escolheu um bairro da Cidade, onde selecionou um grupo de 50 crianças, para iniciar uma turma-piloto. A partir daí, a idéia de ampliar o trabalho, através da criação de uma ONG, foi ganhando corpo.

Atualmente, a EDISCA possui cerca de $380^{3}$ alunos, entre 7 e 20 anos, oriundos de 17 comunidades da periferia de Fortaleza. Para fazer parte do Projeto, as crianças passam por uma seleção, conhecida como audição. É uma espécie de aula de dança, em que são avaliados critérios referentes às habilidades e potencialidades que, no entendimento da ONG, são necessários ao bom desenvolvimento dessa modalidade artística: musicalidade, coordenação motora, flexibilidade e lateralidade. Só participam das audições crianças que atendam ao seguinte perfil social: pertencer a uma das comunidades atendidas; comprovar carência de recursos materiais; ter idade entre 7 e 10 anos (idade-limite para ingressar); estar matriculada na escola formal; ter vínculo familiar (a EDISCA não atende a crianças em situação de rua).

A partir dos critérios listados acima, perce-

${ }^{3}$ Esse número é referente aos alunos que se encontravam freqüentando a Escola em dezembro de 2004, segundo o Relatório Anual 2004, realizado pela própria instituição. be-se a intenção preventiva da educação que esta escola propicia. O perfil social exigido pode ser entendido como o "modelo ideal" do aluno que pode ser trabalhado, ou seja, aquele que ainda não se "desviou" da rota das instituições reconhecidas como espaços naturais e "normais" para a socialização primária de crianças e jovens: família e escola.

O trabalho de prevenção justifica-se pela origem social dos alunos, principalmente levando-se em conta a pressuposição de que a família sozinha não dará conta do trabalho de socialização, imprimindo, nessas crianças e adolescentes, a "moralidade e a disciplina necessárias" para tornálos "adultos normais". Esse trabalho, no entender dos dirigentes da ONG, quanto mais cedo for iniciado, melhores resultados produzirá. Nesse sentido, o critério da idade mínima para ingressar na EDISCA passa a ter um significado importante. No início, esse critério não era tão rigoroso. Assim, recebiam-se adolescentes menores de 18 anos e não apenas crianças. A redução da idade-limite deveuse ao desejo de um trabalho mais "eficiente", no que concerne à prevenção da "situação de risco". É o que demonstra a fala a seguir:

... a gente tem pego as crianças numa idade mais tenra, porque a gente vê que o trabalho é mais acelerado, (...) quanto mais novinha melhor. Isso, de certa forma, te livra... te bota mais distante. (...) o ideal é pegar a criança sem ela estar envolvida com drogas, estando vinculada à família, sem ter tido caso de prostituição (...) na hora que você pega a criança sem ter passado por esses traumas (...) ela está muito mais possível, né? ${ }^{4}$

Passar na audição não é garantia de permanecer na EDISCA. O candidato(a) tem de cumprir uma espécie de estágio probatório de um mês. Durante esse período, o aluno(a) recebe uma visita domiciliar, feita por uma equipe da ONG, ocasião em que é aplicado um questionário socioeconômico, objetivando conhecer melhor a realidade do aluno, bem como estabelecer uma primeira aproximação com a família. Além disso, família e aluno a par do Regimento da Escola, onde estão contidos ${ }^{4}$ Coordenadora da EDISCA, em entrevista realizada por
mim, em 1999 . 
os direitos e deveres dos alunos, pois só fica quem se adaptar às regras.

Ao término do período probatório, os que ficam recebem uniformes para as aulas de dança e passam a usufruir de vários serviços e atividades, que, atualmente, estão agrupados em três áreas distintas. ${ }^{5}$

\section{ÁREA PEDAGÓGICA}

A área pedagógica compreende as atividades de "fortalecimento do ensino formal", "informática educativa” e "preparação para o mundo do trabalho".

As ações de "fortalecimento do ensino formal” incluem aulas de reforço, disponíveis para os alunos que apresentem baixo desempenho nas disciplinas do currículo escolar, serviço de biblioteca e atividades esporádicas chamadas de "oportunidades educativas": oficinas de contação de histórias, visitas a museus e exposições, gincanas culturais, dentre outras atividades.

A busca, através de parcerias com instituições privadas de ensino, de vagas para os alunos da EDISCA nesses estabelecimentos é outra estratégia de "fortalecimento do ensino formal”. A iniciativa demonstra a descrença na qualidade do ensino ministrado pelas escolas públicas freqüentadas pela maioria dos alunos da ONG.

A partir de 2003, 75\% dos alunos passaram a ter acesso às aulas de informática ministradas na própria instituição. Na proposta pedagógica, essa atividade é nomeada, juntamente com a "preparação para o mundo do trabalho", de "Passaporte para o Futuro", demonstrando a intenção de contribuir com a construção de saberes técnicos necessários à inserção profissional, não necessariamente ligados à arte.

' A EDISCA é uma instituição dinâmica, seus princípios, atividades e forma de organização estão em constante processo de construção. Assim, é importante frisar que as atividades e projetos aqui descritos, bem como os dados estatísticos, têm como base os relatórios anuais de 2003 e 2004 . Essa ressalva torna-se importante pelo fato de que algumas atividades aqui apresentadas podem ter deixado de existir no ano seguinte, assim como outras podem ter sido incluídas.
Pelo Programa de Preparação para o "Mundo do Trabalho", a EDISCA mantém parcerias com o Banco do Brasil (Programa Menor-estagiário) e com a creche do Fórum Clóvis Beviláqua, que garantem estágios remunerados para alguns alunos da Instituição.

\section{ÁREA ARTÍSTICA}

A ONG, pela trajetória e pelo que o nome sugere, nasceu da idéia de tomar a dança como um instrumento pedagógico para promoção da “integração social”. Assim, as aulas de dança foram a primeira atividade a ser oferecida; tudo o mais foi incluído tendo a dança como referência.

Apesar de não adotar o balé clássico nos espetáculos, referentes desse estilo de dança são utilizados na escola de dança, para orientação do comportamento dos alunos, mesmo porque o estilo é tomado como base técnica para a formação de todos os bailarinos.

De acordo com Süffert (1994, p. 63), o balé pode ser entendido como ritual ${ }^{6}$ performativo destinado a construir o mundo do balé e seus participantes, os bailarinos. Assim, a autora distingue três etapas do balé como ritual: feitura das aulas, ensaios e espetáculos. Em torno dessas etapas, percebese uma série de práticas e símbolos que conferem sentido ao ritual. Vestimentas, normas comportamentais, entre outros elementos, são defundamental importância para tornar-se bailarino (a).

Na EDISCA, as características da clientela conferem ao ritual significados mais amplos, visto que, além das aulas e ensaios, outras práticas entram em cena para complementar a formação dos alunos.

A dança exige um habitus específico, nos

\footnotetext{
O ritual é entendido aqui como um "sistema de comunicação simbólica culturalmente construído”, organizado em torno de práticas sociais formais e estereotipadas que se prestam a pensar os processos sociais e resolver conflitos. Nesse sentido, pode-se dizer que o ritual sempre comunica uma determinada visão de mundo, ao mesmo tempo em que faz algo, já que possui um objetivo culturalmente determinado (Tambiah apud Süffert, 1994, p. 64)
} 
moldes do que, em Sociologia, chama-se socialização secundária ou específica. Acontece que o processo de socialização primária, em que os alunos da ONG adquiriram o habitus primário (Bourdieu, 1998, p. 145), não confere a essas pessoas o reconhecimento perante a ordem social dominante.É que, tendo sido adquirido no seio de família pobre, é marcado por disposições tidas como pouco condizentes com o modo "civilizado" de ser. São modos de comer, andar, falar, vestir, reveladores da barreira que separa os pobres das outras camadas sociais que "gozam de inúmeros privilégios, entre eles o de receber "educação" (Zaluar, 1995, p. 11).

Se, por um lado, as atividades da EDISCA visam à concretização do "ser bailarino", por outro, remetem a um processo de socialização através do qual os alunos são estimulados a incorporar as disposições de um habitus diferente do que trazem do lugar social de origem. São valores, gostos, formas de agir e pensar que trazem a marca do "estigma territorial" da periferia, lugar social que, ao ser tomado como "inferior", descredencia o habitus nele construído para inserção na sociedade dita "civilizada".

Nesse sentido, o processo educativo ali implementado traz em si, na sua perspectiva preventiva, uma missão civilizadora, nos moldes do que Elias (1994) chama de Processo Civilizador.

O conceito de civilização, segundo esse autor, expressa a auto-imagem que alguns povos (sobretudo do Ocidente) têm de si mesmos, ou seja, a consciência de superioridade de seu comportamento em relação ao de outras sociedades. A auto-imagem foi sendo constituída ao longo do desenvolvimento histórico das sociedades ocidentais e trouxe consigo modos de conduta, costumes, boas maneiras, sentimentos de vergonha, medo etc., considerados hoje como típicos do homem civilizado. Assim, civilização é, antes de tudo, o resultado de um condicionamento, um "adestramento" dos homens, que imprime nos corpos o que é socialmente instituído.

Como a imagem, socialmente construída, do bailarino está associada, mais do que a de qualquer outro profissional, aos referentes comportamentais da esfera social dita civilizada, o aprendizado desses referentes transforma-se em necessidade que a esta escola busca suprir, e os alunos passam a aderir e a defender como essencial à sua formação, como testemunha o seguinte depoimento:

...da EDISCA eu recebi uma grande ajuda, né, na minha educação. Principalmente tive oportunidade de conhecer vários lugares, de comer de talheres, falar direito, como se comportar nos lugares, falar português corretamente."7

As aulas de dança são o carro-chefe da instituição e são oferecidas a todos os alunos. No entanto, o fato de todos terem acesso a elas não significa que tenham a mesma relação com essa atividade. O sonho de ser bailarino, que motiva a maioria dos alunos a buscarem uma vaga nesta escola, não é completado pela grande maioria, nem dentro, nem fora da ONG. Para explicar tal incompletude, remeterei o leitor aos espetáculos bianuais oferecidos pela escola.

A EDISCA montou nove balés, até o momento: Brincadeiras de Quintal, O Maior Espetáculo da Terra, Elementais, Jangurussu, Koi Guera, Duas Estações, Mobilis, Demoaná e Urbes Favela.

A ONG ganhou notoriedade e reconhecimento a partir de 1995, ano da montagem e estréia do balé que passou a ser sua marca registrada: o Jangurussu. Inspirando-se na realidade das pessoas que, à época, viviam e trabalhavam no aterro sanitário de Fortaleza, com Jangurussu, a ONG criou um espetáculo-denúncia, que conseguiu transformar em arte o cotidiano permeado de miséria e injustiça social do lugar.

O espetáculo transformou-se em fenômeno de público e de crítica, e a ONG passou a receber convites para se apresentar, em diversos lugares do Brasil e do mundo, de modo que traz no currículo apresentações em várias capitais do País, na Itália, França, Áustria e Alemanha.

As apresentações já seriam suficientes para transformar os espetáculos no grande objeto do desejo dos alunos da EDISCA, visto que a

\footnotetext{
${ }^{7}$ Lia, ex-aluna da EDISCA.
} 
concretização do ser bailarino passa, fundamentalmente, pela subida ao palco. No entanto, para os alunos da ONG, participar de um espetáculo assume também a conotação de ter acesso a lugares, coisas e sentimentos que somente os componentes dos balés podem ter, como, por exemplo, viajar para outros países e hospedar-se em hotéis de luxo.

Mas o percurso da periferia ao palco ${ }^{8}$ não é completado por todos os alunos. A maioria fica no meio do caminho. Dos 463 matriculados, em 2003, por exemplo, apenas 27 foram selecionados para participar do balé Mobilis.

No contexto da EDISCA, esse dado é importante, porque os que participam dos balés são quase sempre os mesmos alunos, ou seja, os mais antigos, que já estão preparados para garantir a continuidade da ONG, já que a sua imagem é vendida através dos espetáculos. Significa também que se cria uma distinção entre os alunos. Quem não chega ao palco tem frustradas as expectativas de usufruto das vantagens de ser bailarino(a) da escola.

Até 1999, a seleção era feita através de uma aula. Aos candidatos eram passadas as coreografias do espetáculo e, à medida que erravam ou mostravam baixo desempenho, iam sendo cortados. Com a criação, no referido ano, do Programa Corpo de Baile, a seleção passou a ser feita anteriormente à montagem do balé e participam dela apenas os componentes do Corpo de Baile.

Quem participa do Programa, atualmente 25 alunos, passa mais tempo na ONG para se dedicar à dança e, em troca, recebe uma bolsa mensal, de 35 a 100 reais. A bolsa, por menor que seja, é um outro elemento de distinção entre quem faz e quem não faz parte do Corpo de Baile.

Em seus últimos balés, a ONG adotou uma nova estratégia: envolvimento de todos os alunos, no que se refere à subida ao palco e à produção e concepção do espetáculo, através do projeto Dançando a Vida que resultou nos balés Demoaná (2004) e Urbes Favela (2006).

Além da dança, a escola também oferece aulas de Artes Plásticas, canto-coral e teatro.

${ }^{8}$ Ver Freitas, 2000.

\section{ÁREA SOCIAL}

Com os serviços oferecidos na área social, a ONG objetiva assegurar as estruturas básicas e os meios necessários para a participação dos educandos nas diversas atividades. São componentes da área os Programas de Nutrição e Saúde, acrescidos dos Grupos de Convivência, pelos quais os alunos são levados a discutir temáticas sociais diversas, ${ }^{9}$ e das recentes atividades de Articulação Comunitária, que objetivam maior aproximação da ONG com as comunidades de origem dos alunos.

Como a dança é a atividade principal da ONG, os outros programas foram montados em função dessa atividade. Justificando a criação do programa de nutrição, por exemplo, os membros da EDISCA indagam: "Como se sustentar numa ponta, de barriga vazia? Como fazer piruetas, se a anemia não dá ânimo”? (EDISCA, 1999, p. 109)

Após conseguir recursos para montar um refeitório, a escola passou a oferecer uma refeição diária para todos os alunos. O programa de nutrição não se preocupa apenas em fornecer alimentação, pois, de acordo com a ideologia da escola, "o tipo de comida, a forma de servir, o comportamento à mesa, o combate às doenças, a formação de hábitos alimentares e de higiene formam um só pacote" (EDISCA, 1999, p. 137).

A EDISCA põe em prática, através desse programa, o ensinamento de uma série de "técnicas corporais" ${ }^{10}$ que, através das "disciplinas", ou seja, "dos métodos que permitem o controle minucioso das operações do corpo" (Foucault, 1987, p. 126), imprimem, no corpo, as disposições de determinado habitus que, estando de acordo com a ideologia dominante da sociedade, opera como "natural”, "normal” e produz um efeito de submissão (concordância).

\footnotetext{
Como exemplo de temas discutidas nesses grupos, temos os que fizeram parte da programação de 2003: Papéis Sexuais e Valores; Identidade e Racismo; Ser Criança/Ser Adolescente; Minha Escola; Papel do Adolescente na Família.

${ }^{10}$ A expressão "técnicas corporais" é utilizada aqui tal como Mauss (1974, p. 213) a define: "as maneiras como os homens, sociedade por sociedade e de maneira tradicional, sabem servir-se de seus corpos".
} 
Na escola de dança, as disciplinas empregadas nos momentos da refeição exemplificam bem como se processa a incorporação de uma das facetas do habitus que a ONG deseja que os alunos assimilem. Assim, as regras devem ser seguidas à risca na hora da refeição: comer de talher, manter boa postura à mesa, não falar de boca cheia.

Os cuidados de higiene requerem atenção especial na EDISCA. Os alunos, em razão da origem social, habitam regiões da Cidade onde, muitas vezes, não têm acesso a serviços de esgotamento sanitário, água encanada, coleta de lixo, ficando expostas a doenças comuns em lugares insalubres, como pediculose, micoses e parasitoses. Assim, os cuidados com a higiene corporal, além de serem requisitos indispensáveis à beleza e boa apresentação pessoal exigida para bailarinos (as), assume, no discurso da ONG, conotação médica. ${ }^{11}$

Através de seu programa de saúde, a escola distribui para os alunos kits com produtos de higiene corporal e promove campanhas educativas destinadas a desenvolver novos hábitos de higiene.

A instituição possui um ambulatório médico com auxiliar de enfermagem em tempo integral e uma médica que atende a alunos e familiares. Por meio de convênios com laboratórios, empresas e órgãos oficiais de saúde, garantem a distribuição de medicamentos, óculos e coletes ortopédicos e realizam as seguintes ações: campanhas de vacinação, aplicação de flúor, exame biométrico, atendimento odontológico, oftalmológico, ginecológico, fonoaudiológico e realização de pequenas e grandes cirurgias.

Através dos serviços e atividades que oferece, a escola tem buscado constituir-se como espaço em que crianças e adolescentes da periferia podem experimentar formas de sociabilidades diferentes das que experimentariam, sem a intervenção da ONG. Como a pretensão é livrá-los da "situação de risco", moldando comportamentos atra-

${ }^{11} \mathrm{O}$ discurso que associa higiene, beleza e saúde possui uma história de, pelo menos, um século, no Brasil. Higienistas e moralistas da virada do século XX já faziam da higiene do corpo, da casa e dos utensílios um pressuposto fundamental da saúde, sobretudo das mulheres: (Sant'Anna, 1995). vés de um processo civilizador que aponta na perspectiva da normatização ou adequação aos comportamentos dominantes, as sociabilidades ali vivenciadas vão formar um "híbrido"12 em que operam, ao mesmo tempo, "lógicas estruturais de dominação e lógicas sociais de inovação" (Correia, 2003). Evocando funções sociais para a arte, a escola de dança desenha a crença no seu valor pedagógico e terapêutico, como instrumento de desenvolvimento humano e, conseqüentemente, de construção de um mundo menos excludente. Assim, inova e inscreve sua prática no que chama de "Pedagogia Interdimensional", que prioriza a estética como ética do futuro, apontando para a concretização de ações emancipatórias assentes na proposta da educação transformadora. Nesse processo, o trabalho com a auto-estima é apontado pela ONG como o principal ganho conseguido com os alunos via arteeducação:

O ganho real do trabalho com as meninas é a coisa mais subjetiva... Auto-estima pra mim é uma coisa desgastada, como "eu te amo", como uma série de palavras e de frases que de uma certa forma perdeu meio que o significado de tanto que foi mal utilizada. Mas, sem isso... Sem a coisa de se ver possível, de se ver capaz, de já ter tido a experiência de conquistar algumas coisas... (Coordenadora da EDISCA).

Analisada a partir do que acontece durante a vivência na Instituição, a escola tem possibilitado aos alunos os seguintes ganhos: garantia de acesso aos bens e serviços que a ONG propicia, estabelecendo, portanto, uma "mudança social" temporária, já que esses alunos passam a diferenciar-se das pessoas que gozam das mesmas condições de vida que eles e a aquisição de novas disposições do habitus em forma de novas linguagens corporais e elementos subjetivos, o que pode lhes permitir melhor movimentação nas esferas ditas "civilizadas" da sociedade.

No que se refere à aquisição de novas disposições do habitus, deve-se ressaltar que, ao ser construído a partir dos padrões de uma arte espe-

${ }^{12} \mathrm{O}$ conceito de hibridação aponta para a possibilidade de combinar elementos ou dimensões da vida social, habitualmente, pensados ou apresentados como separados. 
cífica ligada ao modo de ser e ao gosto das elites o balé clássico -, o habitus, ao reproduzir comportamentos dominantes, gera um conflito entre o mundo da periferia e o mundo da dança (na forma como a escola a concebe). O conflito pode ser percebido, por exemplo, quando os alunos revelam o desejo de não voltar para casa, quando viajam, ou mesmo quando se percebem executando modos e atitudes que contrastam com os dos familiares. Chamo a atenção, portanto, para o fato de que os processos de educação não-formal desenvolvidos através da arte com crianças e jovens desfavorecidos, por mais inovadores que se reivindiquem, não se fazem sem a intermediação de conflitos temporais (o antes, o durante e a incerteza do depois) e espaciais, resultantes do encontro de experiências de sociabilidade construídas a partir de espaços sociais distintos.

O processo de hibridação, na EDISCA, não se dá apenas no âmbito dos limites da arte-educação como reprodução e inovação. Os limites entre o formal e o não-formal, em termos de educação, também são vivenciados ali, uma vez que a crescente preocupação com as atividades de reforço ou complementação da escola formal encontra-se cada vez mais presente na ONG. Da mesma forma, as fronteiras entre ambiente doméstico e institucional são traçadas com linhas muito tênues, sobretudo se levarmos em conta as atividades e serviços oferecidos, que apontam para os cuidados e afetos diversos que, para os alunos, sobretudo os mais antigos, fazem desta escola de dança a "segunda casa".

O horizonte que dá sentido a esse processo é a promessa de um futuro melhor para aqueles a quem foi dada a oportunidade de vivenciar o que a escola oferece.

Pensar as repercussões dessa experiência, em termos de outra temporalidade (o depois da passagem pela ONG), é fundamental para se perceber como as experiências vivenciadas e o aprendizado que delas resultou refletem nas trajetórias pós-institucionais dos indivíduos. Ninguém melhor que os principais herdeiros dessa experiência, ou seja, aqueles que dela participaram no passado como alunos, para dizer dessa repercussão.

\section{TRAJETÓRIAS DE EGRESSOS}

Para compor a pesquisa sobre os egressos dessa escola, contatei ao todo vinte e nove jovens, com tempo de permanência na ONG entre dois e doze anos. Do universo citado, elegi sete egressos para reconstituir suas trajetórias. A escolha foi feita de acordo com os seguintes critérios: tempo de permanência na EDISCA; diferença de trajetórias na escola e diferença de trajetórias pós-institucionais, ou seja, busquei jovens que, depois da saída, seguiram caminhos diversos, independentemente de estarem ou não envolvidos com arte, ou de estarem ou não no mercado de trabalho.

Neste artigo, recomponho as trajetórias de apenas três dos sete jovens entrevistados: Vera, Léa e Nina, embora utilize, na análise, trechos de fala dos outros: Ivo, Malu, Lia e Bia, ${ }^{13}$ que possuem o seguinte perfil:

Ivo - vinte e quatro anos de idade, menos de quatro anos de EDISCA. Caçula de família de dezessete filhos. O pai, aposentado, era pescador, e a mãe, que faleceu quando ele tinha quatorze anos, era dona de casa. Começou a trabalhar aos onze anos como ajudante de garçom, em barraca de praia. Entrou na EDISCA aos dezessete anos e, lá dentro, trabalhou como montador de cenários dos espetáculos e, por isso, teve a oportunidade de fazer algumas viagens. Terminou o ensino médio. Após a saída da ONG, ingressou no Colégio de Dança do Ceará, ${ }^{14}$ depois mudou-se para o interior de São Paulo, onde trabalhou como peão de obra. Ingressou no curso de Ciências Sociais na UNESP de Araraquara, mas abandonou-o para dedicar-se à dança. Fez vários cursos de aperfeiçoamento em dança. Ministrou cursos de extensão em dança na UNICAMP e na UNESP de

${ }^{13}$ Os nomes são fictícios, para preservar a identidade dos jovens.

${ }^{14}$ O Colégio de Dança do Ceará foi criado pela Secretaria de Cultura do Estado, através do Instituto Dragão do Mar de Arte e Cultura e da Fundação Nacional de Artes FUNARTE (órgão ligado ao Ministério da Cultura), com o objetivo de incrementar e incentivar o ensino, a prática e a criação de dança no Estado. A Instituição funcionou durante quatro anos (de 1999 a 2002), oferecendo cursos de capacitação para bailarinos, ensaiadores, coreógrafos e professores de dança. 
Araraquara. Fez estágio na Companhia Quasar de dança, em Goiânia e, hoje, de volta à Fortaleza, está à frente da Companhia Etra de Dança.

Malu - vinte e dois anos, órfã de pai desde os dois anos de idade. A mãe terminou o ensino fundamental e trabalha numa empresa de beneficiamento de camarão. Entrou na EDISCA aos onze anos de idade e permaneceu por oito anos. $\mathrm{O}$ tempo na ONG foi dividido com outras atividades, sobretudo os cursos profissionalizantes, patrocinados pela mãe. Fez parte do Corpo de Baile, mas só dançava em Fortaleza, porque começou a trabalhar aos quinze anos como estagiária de uma loja de roupas. Depois foram três anos e meio na Pizza Hut, onde passou por vários setores, da confecção de pizzas à recepção de clientes. Terminou o ensino médio, tentou vestibular para administração de empresas, mas não passou. Saiu da EDISCA aos dezenove anos e, atualmente, trabalha no setor financeiro de uma loja de jóias banhadas a ouro.

Lia - vinte anos de idade, filha de uma empregada doméstica com um pedreiro, ambos com ensino fundamental incompleto. Entrou na EDISCA aos seis anos de idade e permaneceu até os treze. Foram sete anos, ao longo dos quais teve a oportunidade de participar de dois balés e viajar para o Rio de Janeiro, São Paulo, Brasília, Recife, Campina Grande, Salvador e Paris. Lia abandonou a ONG porque se envolveu com drogas. Saindo da EDISCA, abandonou também a escola formal, antes de concluir o ensino fundamental. Engravidou aos dezessete anos e hoje é mãe de duas meninas. Nunca trabalhou e vive com o companheiro, pai das duas filhas, que, assim como ela, está desempregado.

Bia - tem vinte e dois anos de idade, é filha de um soldador com uma costureira, ambos com ensino fundamental incompleto. Entrou na EDISCA aos oito anos e passou dez anos como aluna da Instituição. Aos dezoito, foi convidada para ser professora da ONG e permanece no cargo até hoje. Participou de todos os balés da EDISCA, até Mobilis, e, conseqüentemente, de todas as viagens, dentre elas as internacionais para França,
Áustria, Itália e Alemanha. Concluiu o ensino médio e tentou vestibular para Serviço Social, sem obter sucesso. Atualmente, pensa em prestar novo vestibular para Educação Física, para ampliar a experiência em dança, embora seu sonho seja seguir a carreira de psicóloga. Além de professora da EDISCA, a jovem está à frente da Companhia Guindar de Dança que montou com outras três ex-alunas da ONG.

\section{VERA E O SONHO DE UMA NOVA EDISCA}

Vera nasceu em Fortaleza e, até os dezenove anos de idade, viveu com a família no Morro Santa Terezinha, Conjunto Popular da Zona Norte da cidade. No ano da entrevista, ia completar vinte e cinco anos. Desde criança, acalentava o sonho de ser bailarina, mas os pais não tinham condições de pagar-lhe aulas de balé. A mãe estudou até a quarta série do ensino fundamental e é dona de casa. O pai concluiu o ensino médio e trabalha numa fábrica de castanha de caju, recebendo um salário (cerca de 800 reais) que, durante muito tempo, foi a única fonte de renda da pequena família: Vera tem um irmão mais velho. Os pais, depois de vivência complicada, que deixou traumas na jovem - o pai batia na mãe e começou a traí-la desde cedo-, separaram-se em 2003.

Entrou na EDISCA em 1991, aos doze anos, através da primeira seleção feita pela fundadora da ONG. Tendo sido da primeira turma, Vera acompanhou de perto a trajetória da Instituição até 2000 , ano da sua saída. Foram quase dez anos, ao longo dos quais teve a oportunidade de viver muitas experiências. Fez parte de seis balés e, por conta deles, viajou para a Itália, França, Brasília, São Paulo, Rio de Janeiro, João Pessoa, Recife e Salvador.

Em 1995, tornou-se professora de dança da ONG. Ela foi a primeira aluna (e única até 2000) a ser incorporada ao quadro de professores. Na época, tinha dezesseis anos, e o convite veio depois que Vera comunicou à direção da escola que ia sair para trabalhar.

Vera sempre figurou como um modelo de 
disciplina, determinação e bom desempenho dentro da EDISCA até o ano de 1999, quando, aos dezenove anos, uma gravidez inesperada provocou uma crise na ONG, ocasionando sua saída mais tarde. O episódio da gravidez é lembrado como a razão dos momentos mais difíceis e decepcionantes que viveu lá dentro, uma vez que foi tomada pela direção como algo que contrariava as orientações da Instituição.

O desconforto e a insatisfação com a situação que se instalou após sua gravidez foram os principais motivos da sua saída em novembro de 2000, mas não os únicos. O sentimento de acomodação e o desejo de conhecer outros espaços e trilhar novos rumos de forma autônoma e independente também contribuíram.

Após a saída da EDISCA a vida de Vera tem sido cheia de desafios, incertezas e, sobretudo, de idas e vindas não só na vida profissional como na vida pessoal. Na vida pessoal, já se separou do companheiro, pai de sua filha, várias vezes. $\mathrm{Na}$ vida profissional, o primeiro desafio foi a seleção para o Colégio de Dança do Ceará.

A permanência no Colégio de Dança foi de um ano e, nos primeiros meses, a sua dedicação às aulas era exclusiva. Depois, começou a trabalhar para poder ajudar o companheiro no sustento da filha. Em seu currículo, encontram-se as seguintes experiências: quatro meses como professora de balé em uma creche; dois anos como animadora cultural em um hotel localizado numa praia cearense; vinte e três dias assumindo a mesma função em um hotel de Portugal.

Após essas experiências, Vera, que terminou o ensino médio, mas não ingressou na universidade, resolveu investir num projeto próprio e convidou outras ex-alunas da EDISCA para montarem um grupo de dança e iniciarem um trabalho social, semelhante ao da ONG, com crianças e adolescentes do seu bairro.

O esforço testemunhado na EDISCA faz com que Vera siga em frente, na determinação de levantar o próprio trabalho social, mesmo ainda não tendo nenhum retorno financeiro e enfrentando inúmeras dificuldades que paralisaram o trabalho pou- co tempo depois da primeira seleção de alunos.

... o projeto social nós hoje somos multiplicadoras, repassadoras, né? De todo o trabalho que foi feito conosco dentro da EDISCA. A gente acredita que se teve um resultado, se fez muita diferença na nossa vida ter feito parte de um projeto social, se trouxe muitos benefícios, se foram muitas oportunidades boas, algumas transformadoras, a gente acredita que o mesmo possa acontecer também na vida de outros jovens, de outras crianças, né? A gente quer poder proporcionar o mesmo para outras crianças.

Além do projeto social, a jovem está à frente da Experimentvs Cia. de Dança, formada por oito ex-alunos da escola de dança e inserção social.

Apostando na criação de uma nova EDISCA, Vera atesta, ao falar dos objetivos do trabalho, a positividade da experiência vivenciada na ONG, na sua trajetória e de outros jovens. A EDISCA trouxe "benefícios", "fez diferença" na vida, "transformou". As disposições do habitus incorporadas na ONG são marcas que carrega em sua trajetória e estão para além das disposições para a dança.

Minha mãe me ensinou muita coisa. Ela me deu uma educação, tanto a mim quanto a meu irmão, maravilhosa, sabe? Mas eu digo que se eu não tivesse feito parte da EDISCA, com certeza também não seria uma pessoa louca, uma pessoa ruim não. Eu seria uma pessoa maravilhosa também, né? Mas, na EDISCA, eu aprendi desde a maneira de me comportar, de falar, de agir, de me vestir, eu aprendi muito. Eu tava sempre ali no convívio daquelas pessoas inteligentes, interessantes, experientes, sabe?

Tudo na vida de Vera, hoje, desde os projetos de futuro, tem a EDISCA como referência. Por isso, a experiência socializadora vivenciada na ONG assume predominância na constituição do seu patrimônio de disposições, que ela busca atualizar, transferindo para novos contextos espaciais e temporais, mesmo porque o tempo de dedicação à EDISCA foi um tempo em que deixou de se dedicar a outras atividades como ela atesta:

Dei muito de mim pra EDISCA. (...) a gente costuma dizer que a escola é nossa segunda casa, né? Eu dizia que a EDISCA era a minha segunda casa. Que eu passava mais tempo na EDISCA do que na minha casa ou na escola. 


\section{LÉA E A PAIXÃO PELO TEATRO}

Léa vai completar vinte anos. Nasceu em Fortaleza e mora nas imediações do bairro do Mucuripe. O pai trabalha no almoxarifado de uma empresa de ônibus e conseguiu recentemente, por exigência da empresa, concluir o ensino fundamental. A mãe, que cursou a segunda série do ensino fundamental, é dona de casa e cuida do filho de uma vizinha. Os pais, que, além dela, tiveram mais dois filhos, separaram-se em 2003.

Léa entrou na EDISCA aos doze anos e passou seis anos lá dentro, mas sua ligação com a arte iniciou quando, aos oito anos, entrou no Projeto Um Canto em Cada Canto, ${ }^{15}$ montado na escola pública onde estudava. Foi nessa mesma escola, por intermédio de uma amiga que já fazia parte da escola de dança, que ficou sabendo da existência da Instituição e resolveu fazer a seleção. Léa deixou o coral para estudar dança por causa do choque de horários, mas, depois de quatro anos na EDISCA, voltou a cantar, porque a ONG montou um coral e ela decidiu participar.

A ligação com o coral daEDISCA fez Léa abrir mão de certas vivências que constituem o grande desejo de todas as crianças que entram lá. Ela, que foi selecionada duas vezes para o Corpo de Baile, nunca dançou nenhum balé ou viajou. Das duas vezes, ela se viu obrigada a decidir entre a dança e outra atividade, por causa do choque de horários e dos conselhos da coordenação, que sempre dizia que ela tinha mais jeito para fazer outra coisa. Na primeira vez, as opções eram o coral e a dança. Na segunda, ela teve de escolher entre ficar no Corpo de Baile e fazer o cursinho pré-vestibular que a EDISCA criou para os alunos. Quando a EDISCA montou um grupo de teatro, a jovem resolveu fazer parte e acabou se apaixonando por essa arte.

Aos dezessete anos, Léa começou a trabalhar para ajudar em casa. A oportunidade do pri-

${ }^{15}$ Esse Projeto foi criado em Fortaleza em 1988, com a proposta de trabalhar a musicalização de crianças e adolescentes da periferia, através da formação de corais. Hoje, o Canto em Cada Canto é uma ONG que conta com corais infantis espalhados em mais de 20 bairros da periferia de Fortaleza, além de cerca de 90 corais em escolas públicas no restante do Estado. meiro emprego, assim como dos outros empregos que conseguiu até hoje, foram dadas pela própria EDISCA. Só no Banco do Brasil, ela cumpriu três temporadas de trabalho: dez meses como estagiária, cinco meses como telefonista e seis meses como escriturária. Trabalhou ainda como estagiária do escritório da EDISCA durante três meses e estagiou na creche do Fórum por cinco meses. Desligou-se completamente da ONG, em julho de 2003, aos dezoito anos. Desde então, dá aulas de dança para crianças de uma escola, emprego que também conseguiu por intermédio da EDISCA, e participa no Projeto Nossos Passos.

Além disso, está estudando para o vestibular. Tentou uma vez para Administração de Empresas - opção influenciada pelo trabalho no banco. Hoje, tem conviç̧ão de que sua vocação está na arte e quer ingressar no curso superior de teatro.

No balanço do aprendizado adquirido, em seis anos de EDISCA, ela explica o que realmente ficou e o que leva para o trabalho atual:

...a EDISCA me ajudou muito na minha vida hoje, não em relação a saber dançar, a saber interpretar, a saber cantar. Me ajudou muito a ter força de vontade, a ir atrás dos meus objetivos. A não ter medo de falar com as pessoas importantes. (...) A saber se dirigir, a saber se comportar, a mostrar sinceridade. Isso foi o que eu mais colhi na EDISCA... Não tanto o balé, a dança. (...) Eu já busquei mais o lado da educação mesmo lá que eles dão lá mesmo. O respeito. Isso foi o que de melhor eu aprendi lá dentro.

Para Léa, foi a EDISCA também que lhe permitiu ter uma vida diferente da que supostamente teria tido sem a interferência da Instituição.

Eu acho que, no exato momento que eu entrei na EDISCA, que eu passei a conhecer outras pessoas, que eu passei a ter outra visão, outros pensamentos, de estudar, de trabalhar, de dançar, de tá ocupada - o meu tempo todo era ocupado - eu fui sempre uma pessoa muito ativa, ocupada, ocupada. Se eu não tivesse conhecido isso, hoje em dia ou eu já seria mãe... Todas as minhas colegas que eu andava, mesmo de verdade assim, o dia inteiro... da minha mesma idade todas já tem filhos. (...) Todas são mães, duas são prostitutas, uma tá destruída mesmo, a vida dela assim, morando horrível, largou dos pais, foi morar com uma pessoa que não tem nada pra passar pra ela, passando muita necessidade. A vida de tudim tá desse jeito e a minha elas vêem a diferença... 
Atribuindo à escola de dança a mudança de rota de um destino que lhe parecia certo para uma jovem da periferia como ela, Léa destaca ainda a preparação para o mundo do trabalho como componente importante da educação ali recebida. Para ela, os empregos, mesmo que precários, sem contrato ou quaisquer outras garantias, valeram pela experiência, pelo aprendizado e, sobretudo, por terem oportunizado certa independência financeira, que lhe permite consumir certos objetos de desejo de jovens cujas famílias, como a dela, mal podem garantir o básico para a sobrevivência.

\section{OEMPREGOCOMOHERANÇADEFAMÍLIA: Nina}

Nina tem vinte anos, nasceu em Fortaleza e mora no Palmeiras, conjunto habitacional da Zona Sul, que abriga uma população cuja renda per capita média mensal é menos de meio salário mínimo. A mãe, que cursou até a $6^{\mathrm{a}}$ série do ensino fundamental, era auxiliar de serviços gerais no Laboratório da Santa Casa de Misericórdia. Atualmente cuida da mãe da dona do laboratório, que tem problemas de demência. O pai de Nina fez o $1^{\circ}$ ano do ensino fundamental. Trabalhava como carpinteiro, mas parou há muito tempo por causa do alcoolismo.

Nina tem uma irmã mais nova, que também foi aluna da EDISCA, e mais quatro irmãos, frutos do primeiro casamento do pai. O sustento da família é garantido pelo salário da mãe, com a ajuda das aposentadorias da avó e de uma tia de Nina.

A entrada na EDISCA aconteceu aos dez anos de idade. Além da escola de dança e das aulas na escola formal, ela foi incentivada pela mãe a fazer cursos para se capacitar melhor para o futuro. Entre os cursos que fez, apenas um de informática foi feito na ONG; os outros, dentre os quais atendimento ao cliente e diversos na área de informática, ela fez fora.

Após cinco anos na escola de dança, Nina foi selecionada para o Corpo de Baile. Nina dançou dois balés. Poderia ter feito parte de outros, mas uma tendinite nos dois joelhos, ocasionada pelos movimentos repetitivos das aulas de dança, obrigou-a a se afastar dos ensaios.

Os balés de que fez parte permitiram-lhe fazer as únicas viagens de sua vida. Viajou três vezes para o Rio de Janeiro, duas para São Paulo e passou dezenove dias em Paris. Além de fazer parte do Corpo de Baile, chegou a participar do coral da EDISCA.

Aos dezoito anos, Nina foi afastada do Corpo de Baile, por causa de desentendimentos com a direção da escola. Para ela que, até então, se mantinha afastada do mercado de trabalho, a saída do Corpo de Baile significou o corte da bolsa, meio salário mínimo, com que reforçava o orçamento familiar. A jovem resolveu sair da escola de dança para trabalhar. O ingresso no mercado de trabalho não foi imediato. Ela gostava de dança e ainda pensava em profissionalizar-se. Daí, seguiu o mesmo caminho que Vera e Ivo: fazer seleção para o Colégio de Dança.

A passagem pelo Colégio de Dança foi rápida, porque Nina, que estava terminando o ensino médio, não foi liberada pela diretora da escola onde estudava para chegar atrasada nas aulas, já que a longa distância entre a escola e o Colégio de Dança impedia que ela chegasse no horário.

Nina ficou entre a dança e a preparação para o vestibular. Acreditando na continuidade do percurso escolar como "meio de alcançar um emprego mais qualificado" (Abrantes, 2003), fez a segunda opção e prestou vestibular para Educação Física. Sem êxito e sem querer adiar ainda mais a entrada no mercado de trabalho, que lhe daria certa autonomia em relação à família, entrou na lógica do “aproveitamento das 'oportunidades' que surgem” (Marques, 2003), que tão bem caracterizam o modelo de experimentação vivenciado pelos jovens nas trajetórias "yô-yô" (Pais, 2001). Assim, resolveu aceitar a proposta de trabalho, trazida pela mãe, no Laboratório de Análises Clínicas da Santa Casa de Misericórdia. Começou ajudando a mãe na lavagem de material, passou para o setor de contabilidade e depois passou a atuar como recepcionista. Tendo concluído, mais tarde, o curso de Auxiliar de Laboratório, ela atualmente também 
ajuda na coleta de sangue.

O emprego de Nina foi arranjado pela mãe, que trabalhava desde criança com a dona do laboratório. A mãe de Nina, por sua vez, conseguiu emprego por intermédio da mãe, avó de Nina, que era doméstica na casa da dona do laboratório. Assim, uma foi herdando a patroa da outra, o que demonstra uma das estratégias de inserção no mercado de trabalho que se impõe aos jovens das camadas desfavorecidas: optar por uma "trajetória conhecida”, ou seja, aquela já experimentada pelo grupo familiar (Galland, 1991, p. 135). A melhor escolaridade e capacitação de Nina - ensino médio, cursos de informática, atendimento ao público e auxiliar de laboratório - garantiram-lhe mobilidade ascendente no emprego: de ajudante da mãe na lavagem de material a recepcionista e auxiliar de laboratório. Mas assumir função de maior status não significa que, em termos financeiros, a mobilidade exista, pois recebe a mesma quantia que a mãe: um salário mínimo.

Na compreensão de Nina, a educação e o jeito de lidar com as pessoas, atualmente usados para atender ao público do laboratório, foram exatamente o mais importante aprendizado que a EDISCA lhe proporcionou.

\begin{abstract}
...a EDISCA ela...no tempo em que eu era de lá ela ensinava muito a gente a ser muito carinhosa com as pessoas... e também ensinava a gente educação... Às vezes tinha aula de etiqueta, tinha aula de inglês, tinha aula de francês, tinha um monte de coisa... ensinava a gente a ter educação e como se portar em vários lugares...cada lugar que você precisa ir você precisa ter um jeito de falar com as pessoas, né? Um jeito de se portar... É, eu acho que é a educação a coisa mais importante.
\end{abstract}

Nina pegou gosto pelo que faz e planeja estudar Farmácia, para dar continuidade ao trabalho na área de saúde. O sonho de ser bailarina, alimentado em mais de oito anos de EDISCA, ela não esqueceu, mas deixa adormecido para um futuro mais distante, pois sua prioridade, no momento, é ingressar na universidade.

\section{DILEMAS E PERSPECTIVAS DA REALÇÃO ENTRE A EDISCA E A ESCOLA FORMAL}

Apesar de não ser uma escola formal, a escola de dança ganha uma importância fundamental na educação do público que atende, extrapolando a importância da própria escola formal. Em seus depoimentos, os ex-alunos atribuem à ONG a "educação" que hoje possuem:

A EDISCA pra mim foi uma escola, entendeu? Eu aprendi... é... eu aprendi a crescer com dignidade, aprendi a crescer com respeito às pessoas, a ter boas maneira... Foi uma escola assim de educação... pra mim foi a principal parte da minha vida... foi uma escola mesmo, foi a segunda casa... (Malu)

Do mesmo modo que Malu, os outros exalunos também associam os ensinamentos adquiridos na ONG à educação em seu sentido mais amplo. A escola formal é pouco citada por eles e, quando aparece nos discursos, é como lugar de aprendizado mais relacionado às disciplinas curriculares e à obtenção de uma certificação. A EDISCA, por sua vez, como extensão da casa e da escola, é lembrada como lugar onde aprenderam coisas que serviram para a vida como um todo. Tal valorização de uma experiência de educação nãoformal deve-se à natureza das próprias atividades oferecidas pela ONG e também à má qualidade do ensino ministrado pelas escolas públicas no nosso País, que mal conseguem dar conta da tarefa de alfabetizar, deixando o público atendido numa situação de extrema desvantagem e defasagem num mundo complexo, individualista e competitivo, que exige dos indivíduos o desenvolvimento de habilidades outras, além dos conteúdos práticos e teóricos destinados a exercer uma profissão. Entrelaçar saber com as dimensões éticas, espirituais, sociais e materiais da vida humana é uma exigência cada vez mais premente no mundo contemporâneo (Gohn, 1998).

A matrícula na escola formal é um dos critérios exigidos para ingressar e permanecer na EDISCA. Na cartilha de repasse da metodologia de trabalho da ONG (1999, p.115), a escola formal 
é valorizada como propiciadora da instrução que serve de base para qualquer expressão de talento, seja dança, música, pintura ou outra qualquer manifestação artística. Ou seja, a escola formal é a base de qualquer trabalho de arte-educação, devendo, portanto, ser reforçada no que se refere à instrução que a ONG proporciona, e isso a EDISCA trata de fazer na prática, através das atividades de fortalecimento do ensino formal e da própria exigência da freqüência à escola como critério para entrar e permanecer na ONG. Nesse ponto, cito o fato, observado nas trajetórias, de os egressos, com exceção de Lia que abandonou a EDISCA e, conseqüentemente, a escola formal, terem conseguido superar significativamente o nível de escolaridade dos pais, alguns até ingressando na universidade.

Pelas trajetórias, percebe-se que o desejo de dançar que os fez ingressar na ONG, criou asas diante do contato com a dança e outras artes, mas, dependendo do percurso de cada um na escola, esse desejo assumiu determinada dimensão. Para alguns, transfigurou-se em objetivo de vida e projeto de futuro a ser perseguido na vida pósinstitucional. Para outros, foi fonte de aprendizados aproveitados na vida, mesmo quando não se optou pela carreira artística, casos de Nina e Malu.

Para os que fazem da carreira artística um objetivo, a ONG aparece como "contexto de emergência de vocações” (Martinho, 2003, p. 9), ou seja, espaço que, ao proporcionar os contatos iniciais com as artes e a descoberta dos talentos, contribuiu, para a constituição da "identidade artística". Comentando o que a fez optar pela profissionalização em dança, Bia deu o seguinte depoimento:

...a EDISCA a gente vê muito também como o lado profissional. É aquela coisa do educador chegar pra educanda e dizer: 'Olha, você é capaz! E você pode através da arte, através da dança transformar a sua vida.' De que maneira? Do talento. De você olhar pra dentro de você e saber que tem um talento que pode ser desenvolvido. Da autonomia, né? Desenvolver os potenciais que existem dentro de você, né? Você descobrir isso. Então, a EDISCA, ela busca caminhos para que as crianças descubram dentro delas uma capacidade que até então elas ainda não sabem que têm dentro de si.
Para eles, além do desenvolvimento de identidade artística, a ONG possibilitou ainda o cultivo de relações que facilitam, no presente, a circulação no meio artístico e até o acesso a determinados espaços e apoios necessários ao encaminhamento da carreira. Vera e Ivo, por exemplo, aproveitaram a experiência na escola de dança para "pescar" o know how da coordenadora para fazer contatos, produzir espetáculos, angariar apoios e falar em público.

Nos jovens que não seguiram percurso artístico e trabalham em áreas completamente distantes, observa-se uma influência das experiências educativas proporcionadas pela família, no encaminhamento dos percursos profissionais. Malu e Nina foram as únicas a terem acesso a cursos técnicos, sobretudo na área de informática, patrocinados pela família e não pela EDISCA. Para Malu, conta ainda a priorização do trabalho, desde cedo, em detrimento da dança; para Nina, a priorização dos estudos.

Para todos, independentemente do tipo de experiência vivenciada na ONG, o maior aprendizado foi em desenvolvimento pessoal, que os tornou pessoas capazes de construir objetivos de vida e lutar por eles, escapando de um destino que lhes parecia provável. Dessa forma, corroboram o discurso da ONG que, ao longo dos seus quatorze anos de existência, sempre colocou, entre os objetivos, o trabalho com a auto-estima:

.... EDISCA me ajudou muito na minha vida hoje, não em relação a saber dançar, a saber interpretar, a saber cantar. Me ajudou muito a ter força de vontade, a ir atrás dos meus objetivos. (Léa)

Na EDISCA, a arte nunca foi pensada como profissionalização, ${ }^{16}$ mas como forma de trabalhar as dimensões subjetivas do sujeito, para que se sinta com possibilidades, para além daquelas que o entorno social mais próximo (a família, o bairro) oferece.

16 Só recentemente, com a proposta de criação de uma companhia de dança, é que a perspectiva de profissionalização começou a ser explicitada pela EDISCA. 
Se, por um lado, trabalhar as dimensões subjetivas é uma faceta importante e necessária a qualquer forma de educação, como alertou Adorno (1986), por outro, revela a limitação das instituições que, não possuindo um projeto claro para o público-alvo, incute-lhes a necessidade de construírem um projeto para si. A limitação é dada pelas condições objetivas do público, uma vez que a transformação da situação de vida passa por uma mudança estrutural, não garantida pelas instituições, sendo a educação apenas uma via possível de mudança.

Construção sociocultural e histórica, a categoria juventude alude à fase de vida marcada, fundamentalmente, pela perspectiva de transição, ou seja, o jovem é pensado como indivíduo situado entre a infância e a fase adulta (Bourdieu, 1983; Pais, 2003). Nessa perspectiva, o processo de transição pensado como "normal" para os jovens é o seguinte: cumprir todas as etapas de escolarização, em seguida, entrar no mercado de trabalho para, depois, sair da casa dos pais e (ou) constituir nova família. Dessa forma, envolvimento com drogas, abandono à escola e "gravidez precoce" são "acidentes" que os desviam do percurso "normal" na transição para a vida adulta. A trajetória de Lia exemplifica bem o que é pensado como trajetória "desviante".

Idas e vindas, na vida profissional e pessoal, que marcam a trajetória de alguns ex-alunos da EDISCA, sobretudo de Vera, Ivo e Léa, também contrariam a linearidade da transição "normal" e não são características peculiares a esse grupo. Antes, exemplificam a situação dos jovens nas sociedades contemporâneas, tornando-os ícones de uma geração que Pais (2001) denomina "geração yô-yô", em alusão ao brinquedo popular, disco ou bola presa a um fio que, fixado a um dos dedos da mão do brincante, que lhe permite fazer movimentos diversos, em vaivém não linear e aleatório, explorando o espaço à sua volta. Assim, a "geração yô-yô" tem, na experimentação, a lógica fundamental: experimenta em todos os campos da vida, agarra oportunidades para depois soltá-las e, a seguir, quem sabe, novamente retornar ao ponto de parti- da. Os movimentos yô-yô utilizados por Pais, como metáfora para descrever os trajetos juvenis, na contemporaneidade, tornam-se ainda mais apropriados quando relacionados aos trajetos de vida dos jovens desfavorecidos.

No geral, o segmento juvenil tem sido apontado como o mais afeito a sofrer as conseqüências das transformações socioeconômicas que afetam as sociedades contemporâneas. Em se tratando de jovens das camadas desfavorecidas, as dificuldades de inserção, nas esferas profissionais e privadas, são maiores ainda, denunciando a condição de vulnerabilidade em que eles se encontram frente aos desafios da transição para a vida adulta. Nesse sentido, as incertezas e instabilidades em relação ao futuro reclamam mudanças das formas de socialização (as ONGs que trabalham com jovens podem ser pensadas como exemplos dessas novas formas) que cada vez mais apontam no sentido do trabalho de "individuação" (Marques, 2003), pautado na preocupação de "encontrar a própria via", de "procurar a realização pessoal" ou a "construção da própria identidade”. O processo tem levado à "biografização" ${ }^{17}$ das transições, em que as orientações e obrigações biográficas, frutos de decisões subjetivas, adquirem importância maior na vida dos jovens. Por isso, o trabalho com a subjetividade, através da auto-estima, impõe-se como fundamental nos processos de educação não-formal.

O movimento que a EDISCA prevê para os alunos é um movimento linear, ou seja, a despeito da "yoyoização" (Bois-Reymond; Blasco, 2004), característica das trajetórias juvenis no mundo contemporâneo, a ONG trabalha no sentido de "renormalizar" as transições, garantindo o cumprimento do que é pensado como processo de transição do jovem "normal".

A reconstituição das trajetórias dos jovens que passaram pela EDISCA revela que a relação entre EDISCA e escola formal é de complementaridade, mas também de concorrência. Se, por um lado, a ONG reforça, através das "ações de fortalecimento

${ }^{17}$ A esse respeito ver Alheit (1995) apud Walther (2004) e Bois-Reymond; Blasco (2004). 
do ensino formal", o aprendizado proporcionado pela escola e complementa com as demais atividades e habilidades ali desenvolvidas, por outro, retira parte do tempo que deveria ser dedicado aos estudos, sobretudo para aqueles que fazem parte dos espetáculos. Ivo, ao ser perguntado pelas principais dificuldades enfrentadas durante a estadia na ONG revelou o seguinte:

Olha, a minha dificuldade maior foi o tempo da escola, EDISCA, EDISCA, escola. Foi difícil, porque eu não sabia se eu... a EDISCA tomava muito o meu tempo e às vezes a escola tomava muito o meu tempo não sei se tu entende essa coisa, ficava uma coisa muito...! Eu tinha que me desligar de alguma coisa, sair de alguma coisa não podia ficar nas duas coisas ao mesmo tempo ou então ficar em uma e dar mais oportunidade pra outra, esquecer a outra, enfim. Era muito difícil, muito difícil essa decisão pra mim, lá na EDISCA. E eu fui pelo um caminho errado. Tomei um caminho super errado, que até hoje eu me arrependo muito, que foi querer mais a EDISCA da dança do que a escola formal... (...) Eu tinha que dar mais atenção à escola e não ao balé, e aí isso pra mim, eu dava mais atenção ao balé e menos à escola. (...) Porque eu tinha que perder aula pra ir pros espetáculos às vezes, e às vezes, eu tinha que tá lá pra montagem, eu tinha que tá mais cedo, eu perdia aula por causa disso e aí eu me prejudicava...

Nina diz que a passagem pela EDISCA foi boa para sua vida, porque lhe permitiu aprender muitas coisas e adiar o ingresso no mercado de trabalho, mas, ao mesmo tempo, a falta de uma maior quantidade de cursos no currículo é imputada ao tempo que dedicou à ONG:

...eu acho que, se eu não tivesse passado pela EDISCA, eu acho que eu teria começado a trabalhar muito mais cedo, ia atrás de um emprego mais cedo, e tinha feito muito mais cursos, entendeu?

Bia, na sua fala, enfatiza que o tempo da EDISCA é o tempo que deixou de dedicar a atividades não vinculadas à dança e aos próprios estudos, já que o seu sonho é ser psicóloga:

... psicologia é porque é uma paixão que eu tenho, mas que se eu fosse fazer hoje com certeza eu dizia assim: eu vou parar de dançar e pra mim me inserir no mercado de trabalho de psicologia eu teria que ralar muito, até porque eu não tenho uma formação dentro dessa área, né? (...) Na minha época, a EDISCA ainda estava se estruturando, né? Os caminhos mesmos que eram criados, os caminhos maiores era a área de dança. Então, foi por isso que a minha formação maior foi dentro dessa área.(...) Depois dos 30, 33, 34, aí eu penso em ir pra essa área de psicologia, que é a época que eu quero parar de dançar que eu quero descansar, porque é pesado.

Pela fala de Bia, fica patente a tensão entre as "oportunidades" e a falta de "oportunidades". Ela afirma as "oportunidades" recebidas na escola de dança, que a têm levado rumo à crescente profissionalização em dança, mas revela o desejo de outra profissão. Dizer que dançar e dar aulas de dança é o que sabe fazer de melhor, pode ser também um jeito de dizer que não teve "oportunidade" de aprender a fazer outra coisa, mesmo porque a EDISCA lhe "tomou" o tempo. Assim, a trajetória de Bia está e sempre esteve condicionada ao que a ONG lhe ofereceu e que ela acolheu, por não saber se lhe seriam dadas outras "oportunidades".

Para os egressos, a EDISCA foi a casa e seus membros a família com a qual se identificaram, bem como o espaço educativo por excelência. Dessa forma, como nos processos de conversão, os alunos passaram a adotar uma visão de mundo mediada pela visão de mundo da ONG. E, mais ainda: passaram a defender as formas de conduta recomendadas, e a educação ali efetuada passou a ser vista como uma necessidade e como o que lhes possibilitou escapar do destino social provável:

Se não fosse ela pra me dar esse objetivo de danca... eu ia fazer o que? Ia surfar, ia tá de papo pro ar como os meus irmãos, alguns, ia tá no meio da rua, como alguns colegas, fazendo nada, andando de bicicleta pra cima e pra baixo, conversando nas esquinas. Até mesmo podia tá usando drogas mesmo, bebendo cachaça, gastando dinheiro, enfim. A EDISCA me ajudou muito assim, eu fico muito feliz de ter passado lá. (Ivo)

Aproveitar oportunidades para tecer o cotidiano e inventar outra vida, outro destino, eis a tônica que percebi na trajetória de vida da maioria dos egressos. Não desperdiçar experiências, pensar tudo como aprendizado.

Dessa forma, a EDISCA, através da "inscrição do porvir nos corpos” (Bourdieu, 1998, p. 211), sob a forma de um outro habitus, abriu espaço, pelo que atestam os egressos, para a mudança ou para o alargamento do espaço de possíveis.

O alargamento, dado pela incorporação de 
novas disposições, é usado para correr atrás de sonhos e objetivos no "mundo de fora" da EDISCA. Assim, os jovens da EDISCA, sob o signo da dupla trajetória, experimentam dupla passagem: do mundo real (o da condição social) ao mundo idealizado pela ONG, para voltar ao mundo real (agora modificado pela visão de mundo construída na EDISCA, pelas possibilidades que acham ter adquirido como patrimônio de disposições pela própria tensão, construída e vivenciada na ONG, entre as condições objetivas e os desejos subjetivos de acesso às formas desejadas de inserção social).

Ao falar das repercussões da passagem da EDISCA na constituição das trajetórias, os jovens dizem da aventura de ser jovem pobre no mundo contemporâneo, sobretudo no cenário urbano brasileiro. Falam de certezas e incertezas, de desafios e conquistas, de desejos e frustrações, de sonhos de futuro, de oportunidades e da falta delas. Falam, sobretudo, da disputa entre trajetórias no horizonte de intervenção da ONG: uma para ser denegada e outra para ser seguida.

Os egressos da EDISCA revelam, nas falas, que os jovens desfavorecidos vivem a tensão da dupla trajetória e, para escapar do destino social provável, fazem-se bailarinos no tempo e no espaço, movimentando-se de acordo com as possibilidades dadas e, ao mesmo tempo, limitadas, pelas experiências socializadoras.

(Recebido para publicação em novembro de 2006) (Aceito em abril de 2007)

\section{REFERÊNCIAS}

ABRANTES, Pedro. Identidades juvenis e dinâmicas de escolaridade. Sociologia, Problemas e Práticas, Lisboa, n. 41, p. 93-115, 2003.

ADORNO, Theodor W. Educação após Auschwitz. In: CONH, Gabriel (Org.) Sociologia. São Paulo: Ática, 1986. (Coleção grandes cientistas sociais).

AFONSO, Almerindo Janela. Sociologia da educação nãoescolar: reactualizar um objecto ou construir uma nova problemática? In: ESTEVES, J.; STOER, S. R. (Orgs.) A sociologia na escola - professores, educação e desenvolvimento. Porto: Afrontamento, 1989.

ANDRADE, Dora. Enfim, o balezão. Jornal Diário do Nordeste, Fortaleza, 26 jan. 2005. Caderno 3. Entrevista.
A fada da EDISCA. Jornal O Povo, Fortaleza, 3 ago.1996. Vida \& Arte, p.4b. Entrevista.

BOIS-REYMOND, Manuela du; BLASCO, Andreu López. Transiciones tipo yo-yo y trayectorias fallidas: hacia las políticas integradas de transición para los jóvenes europeos. Estudios de Juventud. Madrid, n. 65, p. 11-29, 2004.

BOURDIEU, Pierre. A Juventude é apenas uma palavra. In: Questões de sociologia. Trad. Jeni Vaitsman.

Rio de Janeiro: Marco Zero, 1983.

O poder simbólico. Trad. Fernando Tomaz. Lisboa: DIFEL, 1989.

Meditações pascalianas. Trad. Miguel Serras Pereira. Oeiras: Celta, 1998

Razões práticas. Trad. Mariza Côrrea. 6.ed. Campinas: Papirus, 2005.

BRASIL. Lei 8069/90. Estatuto da criança e do adolescente. Brasília: 1990.

CORREIA, André de Brito. Arte como vida e vida como arte: sociabilidades num contexto de criação artística. Porto: Ed. Afrontamento, 2003

DUBAR, Claude. A socialização: construção das identidades sociais e profissionais. Trad. Annette Pierrette R. Botelho e Estela Pinto Ribeiro Lamas. Porto: Porto Editora, 1997.

EDISCA. EDISCA: a arte na construção do humano. Fortaleza: 2004

Uma experiência a partilhar. Fortaleza, 1999. (cartilha de repasse da metodologia da EDISCA)

Uma experiência a partilhar. Fortaleza, EDISCA, 1999. (Fita de Vídeo, color, sonoro)

ELIAS, Norbert. O processo civilizador: uma história dos costumes. Trad. Ruy Jungman. Rio de Janeiro: Zahar Editor, 1994. v. 1

FOUCAULT, Michel. Vigiar e punir. Trad. Ligia M. Ponde Vassallo. 5.ed. Petrópolis, Vozes, 1987.

FREITAS, Isaurora Cláudia Martins de $D a$ periferia ao palco: a ressocialização de crianças e adolescentes da periferia de Fortaleza através da arte. 2000. Dissertação (Mestrado em Sociologia) - UFC, Fortaleza.

Destinos (im)prováveis: trajetórias de jovens egressos de uma experiência de arte-educação. 2006. Tese (Doutorado em Sociologia) - UFC, Fortaleza.

GOHN, Maria da Glória. Educação não formal: um novo campo de atuação. Ensaio: avaliação de políticas públicas na educação. Rio de Janeiro, Fundação Cesgranrio, v.6, n. 21, p. 511-526, out./dez., 1998.

MARQUES, Ana Paula. Outras transicões? configuracõe e problemáticas de socialização juvenil. Sociedade e Cultura 5, Cadernos do Noroeste, [S.l.], v. 21, n. 1/2, p. 141161, 2003. (Série Sociologia).

MARTINHO, Teresa Duarte. Em Torno da constituição do sujeito artístico. In: SANTOS, Maria de Lourdes Lima dos (Coord.) $O$ mundo da arte jovem: protagonistas, lugares e lógicas de acção. Oeiras: Celta, 2003.

MAUGER, Gérard. La “jeunesse” dans les "âges de la vie”: une "définition préalable". Temporalistes, [S.1.], n.11, p. $6-7,1989$

MAUSS, Marcel. As técnicas corporais. In: Sociologia e antropologia. São Paulo: E.P.U./EDUSP, 1974. v. 2.

PAIS, José Machado. Ganchos, tachos e biscates: jovens, trabalho e futuro. Porto: Ambar, 2001.

Culturas juvenis. 2.ed. Lisboa: Imprensa Nacional; Casa da Moeda, 2003. 
SANT'ANNA, Denise Berluzzi de (Org.) Políticas do corpo. São Paulo: Estação Liberdade, 1995.

SÜFFERT, Rátia Romera. Bailarina: imagens da construção de um feminino. 1994. 207p. Dissertação (Mestrado em Antropologia Social) - UnB, Brasília.
WALTHER, Andreas. Dilemas de transición: discrepancias entre las perspectivas de los jóvenes y de las instituciones. Estudios de Juventud. Madrid, n. 65, p.133-150, 2004

ZALUAR, Alba. Cidadãos não vão ao paraíso: juventude e política social. São Paulo: Escuta; Campinas: Editora da Uncamp, 1994.

\section{ESCOLA E ORGANIZAČÃO NÃO GOVER- NAMENTAL: educação formal e não- formal de jovens da periferia de Fortaleza \\ Isaurora Cláudia Martins de Freitas}

Freqüentar uma ONG para ter acesso a atividades educativas destinadas a complementar a formação proporcionada pela escola formal passou a ser uma realidade na vida de muitos jovens desfavorecidos do Brasil, a partir dos anos 90, quando a promulgação do Estatuto da Criança e do Adolescente fez surgir grande número de projetos sociais destinados a garantir os direitos de cidadania de crianças e adolescentes consideradas em situação de risco ou vulnerabilidade social. A partir da reconstituição das trajetórias de sete jovens egressos da Escola de Dança e Integração Social para Crianças e Adolescentes (EDISCA), ONG que realiza trabalho de arteeducação com crianças e adolescentes da periferia de Fortaleza objetivando ampliar-lhes as possibilidades de inserção social, o trabalho analisa as repercussões dessa experiência educativa na vida escolar desses jovens, buscando perceber como as relações de complementaridade e "concorrência”, verificadas entre a ONG e a escola formal, repercutiram na formacão dos jovens da periferia, sobretu\& do no que se refere à construção de ㄱ. novas perspectivas de inserção social e profissional.

Palavras Chave: ONG, educação nãoformal, juventude, trajetórias.

\section{SCHOOL AND NON GOVERNMENTAL ORGANIZATION: formal and non-formal education of Youths of the Periphery of Fortaleza \\ Isaurora Cláudia Martins de Freitas}

To attend an NGO to have access to educational activities ntended to complement the formation provided by formal school has become a reality in the lives of many needy youngsters of Brazil. This has been happening since the 90's, when the promulgation of the Child and Adolescent Statute gave rise to a large number of socia projects. Such projects wer intended to guarantee the rights to citizenship of children and adolescents considered to be at risk or social vulnerability. This work ocuses on the reconstruction of the trajectories of seven youngsters come rom EDISCA (Dance and Socia Integration School for Children and Adolescents). This school is an NGO that carries out work in art-education with children and adolescents from he outskirts of Fortaleza, aiming at ncreasing their possibilities of social insertion. The work analyzes the repercussions of this educationa experiment in the school life of these youngsters. It also seeks to perceive how the complementing and "competing" relationship observed between the NGO and the formal school affected their formation, mainly in what concerns the construction of new perspectives of social and professional insertion.

KEY wORDS: NGO, non-forma education, youngsters, trajectories.

\section{ECOLE ET ONG: éducation formelle et non formelle des jeunes de la}

périphérie de Fortaleza

\section{Isaurora Cláudia Martins de} Freitas

Fréquenter une ONG pour avoir accès à des activités destinées à compléter la formation donnée par l'école formelle devient une réalité dans la vie de beaucoup de jeunes défavorisés du Brésil. En effet, à partir des années 90, la promulgation du Statut de l'Enfant et de l'Adolescent fait surgir un grand nombre de projets sociaux créés pour garantir les droits de la citoyenneté des enfants et des adolescents considérés en situation de risque ou de vulnérabilité sociale. A partir de la reconstruction de la trajectoire de sept jeunes venus de l'Ecole de Danse et d'Intégration Sociale pour les Enfants et les Adolescents (EDISCA), ONG qui réalise un travail d'art/éducation avec des enfants et des adolescents de la périphérie de Fortaleza pour augmenter leur possibilité d'insertion sociale, le présent travail analyse les répercutions de cette expérience éducative dans la vie scolaire de ces jeunes. Il cherche à comprendre comment les relations de complémentarité et de "concurrence", vérifiées entre l'ONG et l'école formelle, ont des répercussions sur la formation des jeunes de la périphérie, surtout en ce qui concerne la construction de nouvelles perspectives d'insertion sociale et professionnelle.

Mots-Clés: ONG, éducation non formelle, jeunesse, trajectoires

Isaurora Claúdia M. de Freitas - Doutora em Sociologia pela Universidade Federal do Ceará, em 2006, com bolsasanduíche na Universidade de Lisboa. Professora Adjunta do curso de Ciências Sociais da Universidade Estadual Vale do Acaraú (UVA), no estado do Ceará. Atuou em vários programas e projetos oficiais na área de infância e juventude. Principais linhas de pesquisa: Sociologia da Infância e da Juventude e Sociologia da Educação. 